\title{
O COMUM E O DISPERSO: HISTÓRIA \\ (E GEOGRAFIA) LITERÁRIA NA ITÁLIA
}

CONTEMPORÂNEA

\author{
Ettore Finazzi-Agrò
}

- (Walter Benjamin. "Sur le concept d'histoire". Oeuvres, III. Gallimard, 2000: 441.)

- (Uma interessante reflexão sobre a experiência do tempo nas sociedades ocidentais e sobre a representação da história moderna como dimensão "catastrófica" encontra-se no importante livro de Salvatore $\mathrm{Na}-$ toli, Progresso e Catastrofe. Dinamiche della modernità. Milão: Christian Marinotti, 1999.)

\begin{abstract}
"O historicismo compõe a imagem 'eterna' do passado, o materialismo histórico retrata a experiência única do encontro com esse passado. Ele deixa que outros se consumam no bordel do historicismo com a meretriz 'Era uma vez'. Ele permanece senhor de suas forças: viril o bastante para fazer explodir o continuum da história."
\end{abstract}

Um dos efeitos mais visíveis das crises epistemológicas ou das "catástrofes" (no seu duplo sentido etimológico de fim e de virada ou reviravolta) pelas quais passaram e continuam passando, de forma quase cíclica, as sociedades e as culturas - prescindindo, sempre mais, dos contextos nacionais e, atingindo, pelo contrário, um nível global - parece ser o de uma revisão do cânone historiográfico. Basta, por isso, examinar, sem muita ordem e sem mesmo limitar a nossa atenção a um ou outro país, aquilo que aconteceu na história européia, para se dar conta de como esta necessidade volta a se propor de forma contundente ao longo do tempo: só para dar alguns exemplos, foi o que aconteceu, justamente, com a descoberta das Américas, levando a uma reavaliação radical da relação do homem com o espaço e o tempo; ou com a Krisis vivida no âmbito do romantismo e do "pensamento negativo", que foi encontrar enfim, no menosprezo do passado e no apagamento da tradição propugnada pelas vanguardas do começo do século XX, o seu clímax e a sua superação; e basta olhar, por fim, para o desequilíbrio e o desabamento das certezas (éticas, políticas, ideológicas...) provocados pelas duas grandes guerras mundiais, obrigando, mais uma vez, a uma reflexão profunda sobre como "fazer a história" num universo de valores em frangalhos, dominado pelo vazio e pela perda. Apesar (ou ao lado) das teorias sobre o "fim da história" ou das propostas tentando assimilar, de modo apodíctico, ficção e história - que é, também, conto ou ilustração orientada de eventos, mas não só; que chegou com certeza a uma conclusão, renascendo todavia de forma diferente, interrogando, jus- 
tamente, o seu próprio estatuto "póstumo" -, temos assistido, de fato, a um extenso e muito interessante debate capaz de levar a um reajuste dos parâmetros de avaliação e de análise do passado que, em vez de apagar a função da historiografia, têm contribuído para confirmar a sua centralidade e relevância num mundo sempre mais virado para uma rasura vertiginosa da memória e/ou da tradição. ${ }^{1}$ E se um dos argumentos contra a hipertrofia ou a patologia do historicismo foi, muitas vezes, a retomada da crítica nietzschiana, devemos todavia levar em conta que, por um lado, a posição do filósofo alemão seja, ela mesma, ligada a uma situação temporal peculiar (o fim do século XIX, em que, com efeito, o papel da historiografia tinha se tornado preponderante e até opressivo, fazendo da História um suporte ideológico fundamental do EstadoNação, com a mistificação e absolutização da Origem), e que, por outro lado, em vez de silenciar todo o discurso histórico, as idéias de Nietzsche tenham, afinal, contribuído para reanimar a reflexão em torno do uso (ou da reutilização) do passado, atravessando e ultrapassando também a denúncia benjaminiana do "bordel do historicismo". É suficiente, nesse sentido, pensar na dívida (tantas vezes explicitada) que Michel Foucault contraiu para com o conceito de "genealogia", teorizada pelo filósofo de Röcken, e na função que essa noção tem desempenhado na elaboração foucaltiana do conceito de "arqueologia”. Não quero, aqui, entrar numa análise pormenorizada das várias propostas elaboradas, sobretudo na segunda metade do século XX, sobre como e por que escrever História num mundo que parecia ser incapaz de superar o trauma da guerra (do massacre, do holocausto...) e que, sobretudo, aparentava ter perdido a confiança no valor hermenêutico que a análise do passado podia exercer na praxe contemporânea. Acho, todavia, que algumas dessas teorias foram decisivas para uma nova interpretação do fato literário, levando a uma redefinição da função e do próprio conceito de "obra" (ou melhor, de "obra de arte") em contextos sociais que pareciam não enxergar mais, ou melhor, que aparentavam entender de forma mecanicista e inconcludente a relação entre o material e o imaginário (e estou, desde já, aludindo a um manual de história literária que rompeu, na Itália, com os câ-

\footnotetext{
${ }^{1}$ Uma reflexão importante sobre o tratamento do tempo nas sociedades contemporâneas e sobre o esquecimento compulsivo (à sombra da idéia do "fim da História") encontra-se no livro de Paolo Virno, Il ricordo del presente. Saggio sul tempo storico. Torino: Bollati Boringhieri, 1999: 51-118.
} 
- (CESARANI, Remo; DE FEDERICIS, Lídia. // materiale e l'immaginario: laboratorio di analisi dei testi e di lavoro critico. $10 \mathrm{v}$. Torino: Loescher, 1979-1984.)

(AGAMBEN, Giorgio. Che cos'è un dispositivo? Roma: Nottetempo, 2006: 20.)

- (DELEUZE, Gilles. Qu'estce qu'un dispositif? Paris, Seuil, 1989; trad. ital.: Napoli: Cronopio, 2007: 11.) nones tradicionais de ensino da literatura nacional). Aquilo que passou das grandes teorias historiográficas para a prática da história literária foi sobretudo, a meu ver, uma nova visão de texto, não mais colocado numa cadeia conseqüencial e incluído num contexto que o justifique de forma plena, mas pensado de forma heteróclita e "não-necessária" (isto é, não necessitada pela situação individual ou coletiva em que foi composto). Dito de outro modo, a relação da escrita literária com o tempo e o espaço foi colocada em questão, assim como a dialética tradição/inovação, abrindo espaço para uma cronologia peculiar, cruzada com a topologia, e levando, por isso, a uma multiplicação infinita de planos temporais que não cabe mais numa definição unívoca. Ao contrário, fica marcada por uma heteronomia irredutível a uma norma (a um nómos) simples e não reversível.

Acho, para voltar a Foucault, que a noção de "dispositivo" que ele nunca definiu de forma sistemática, mas que atravessa, todavia, com nomes diferentes, toda a sua obra-pode constituir uma boa exemplificação dessa nova concepção do discurso literário no âmbito historiográfico. Por um lado, de fato, o "dispositivo" foi visto como "um conjunto de praxes, de saberes, de medidas, de instituições tendo como alvo o de gerir, governar, controlar e orientar num sentido que se pretende útil os comportamentos, os gestos e os pensamentos dos homens"* e, por outro lado, ele foi considerado como "uma meada, um conjunto multilinear, composto por linhas de natureza diferente" (linhas, essas, que "não delimitam nem circunscrevem sistemas em si mesmos homogêneos") $)^{*}$ - a partir, então, dessas interpretações do conceito foucauldiano poderíamos aplicar esta instância complexa aos novos projetos de uma história literária não ligada a uma concepção transcendental ou absoluta do contexto geral em que o fato literário se dispõe, mas, pelo contrário, a um brotar contínuo e a uma contínua contaminação de paradigmas diferentes resumindo ou até engolindo o tempo histórico, ou seja, fazendo da cronologia "um grande carnaval do tempo" em que o discurso ficcional (a "máscara", no sentido nietzschiano) volta de modo incessante. Nessa perspectiva, no renascer da história literária tanto do ponto de vista científico ou de objeto de pesquisa quanto do ponto de vista da aplicação didática (escolar ou acadêmica), a contribuição de um modo diferente de se colocar diante do passado - na sua relação óbvia com o presente - foi, nos últimos anos, patente, e levou, pelo menos no âmbito italiano, à pu- 
blicação de muitas obras, que testemunham, justamente, a necessidade de chegar a um reajuste do cânone durante e depois de um longo período de crise sócio-cultural - cuja conclusão parece estar longe ou sempre adiada. ${ }^{2}$ Para citar um exemplo extremamente significativo, Alberto Asor Rosa, um dos grandes mestres da crítica literária italiana, de formação marxista e autor de obras fundamentais sobre a relação entre literatura e sociedade, organizou e editou uma monumental Letteratura italiana em seis volumes, ${ }^{3} \mathrm{pu}-$ blicada antes por uma grande editora (Einaudi) e há pouco tempo reimpressa e vendida nas bancas graças a um dos maiores jornais italianos (La Repubblica). ${ }^{4}$ Desde o início, ou seja, desde a estrutura escolhida pelo seu organizador, a obra, sem negar as dívidas para com uma certa - e certamente ilustre - tradição historiográfica nacional, aparenta todavia querer repensar o discurso literário desde um ponto de vista original, ou seja, desde uma perspectiva que, não excluindo o seu estatuto específico, tenta adotar uma série multilinear de linhas interpretativas, sem que isso chegue a definir um paradigma hermenêutico único, sem nunca delimitar um sistema privilegiado de análise dos textos.

\footnotetext{
${ }^{2}$ Quem conhece, embora de forma superficial, a história italiana dos últimos cinqüenta anos, sabe que as mudanças, no campo político, social e cultural, foram imensas - a partir do desaparecimento da civilização agrária até o fenômeno das "mãos limpas", levando ao nascimento, às vezes distorcido e manco, de novas formas de participação política, naquela que se costuma chamar de "segunda república" e em que o papel da mídia (e dos "dispositivos" a ela ligados) se tornou preponderante. Alberto Asor Rosa, de resto, aponta para esta "catástrofe" do sistema político-cultural italiano em vários lugares da sua produção intelectual: a partir do seu famoso livro Scrittori e popolo (Roma: Samonà e Savelli, 1965) para chegar ao seu polêmico panfleto Fuori dall'Occidente ovvero ragionamento sull'Apocalissi, (Torino: Einaudi, 1992) passando pela fundamental análise desenvolvida em $\mathrm{Le}$ due società: ipotesi sulla crisi italiana (Torino: Einaudi, 1977.)

${ }^{3} \mathrm{Na}$ verdade, o plano geral da Letteratura italiana organizada por Asor Rosa aparece muito mais amplo e ambicioso: aos seis volumes da obra propriamente dita (Torino: Einaudi, 1982-1986) foram se juntando, nos anos a seguir, quatro volumes consagrados à Storia e geografia, (Ibid., 1987-1989) dois volumes dedicados aos Autori (Ibid., 1990-1991.) e quatro dedicados às Opere (Ibid., 1992-1996), acabando com dois volumes de Dizionario delle opere. (Ibid., 1999-2000) Talvez o verdadeiro remate desta imensa empreitada possa ser considerado o volume Letteratura italiana del Novecento: bilancio di un secolo, organizado ainda pelo mesmo estudioso. (Ibid., 2000).

${ }^{4}$ A atenção de Asor Rosa para a historiografia literária já tinha, aliás, se manifestado em várias obras por ele escritas ou organizadas. Cito aqui apenas os 23 volumes da coleção, por ele dirigida, Storia e antologia della letteratura italiana, (Firenze: La Nuova Italia, 1973-1976) idealmente fechada por um volume, escrito por ele mesmo, de Sintesi di storia della letteratura italiana (Firenze: La Nuova Italia, 1979).
} 
(ASOR ROSA, Alberto. "La storiografia letteraria come operazione di conoscenza". Em: ASOR ROSA, A. (org.). La scrittura e la storia. Problemi di storiografia letteraria. Firenze: La Nuova Italia, 1995: 9-10.)

Assim, a obra, colocada, de modo explícito e com força, no centro do discurso historiográfico (como não poderia deixar de ser, em se tratando de um manual de literatura) se descobre não apenas atravessada por uma série de instâncias heteróclitas (políticas, sociais, institucionais ou simplesmente locais), mas, por sua vez, acaba por atravessar e influenciar todas essas instâncias, organizando-se, também ela, como um "dispositivo" que exerce uma forma de poder sobre os demais poderes que ela, cruzando-se e/ou interagindo com eles, pode modificar. Deixamos a palavra ao próprio Asor Rosa:

A "obra literária" é, a meu ver, um sistema de relações entre possibilidades e níveis expressivos diferentes do homem (em primeiro lugar lingüísticos, mas também sígnicos, fônicos, ideológicos, psíquicos, antropológicos), um sistema de relações sendo organizado segundo uma ordem pela assunção de determinados códigos formais (que existem sempre, ainda a despeito das intençôes do "autor"), e é, ao mesmo tempo, parte de sistemas de relaçôes mais amplos, os quais são, por sua vez, em relação entre si, determinando uma transmigração contínua, uma osmose incessante entre outras ordens, outros códigos formais e estilísticos, outras formas da expressividade e da comunicação humana.

O texto é assim colocado dentro de uma rede virtualmente infindável de práticas discursivas, sendo, porém, ele próprio uma prática que interfere com as demais. E aquilo que fica, como caráter específico do texto, enquanto texto literário, é então apenas a "assunção de determinados códigos formais” sem os quais, na opinião de Asor Rosa, não existiria a obra e, menos ainda, a obra de arte.

Nessa escolha de sublinhar com força a influência do código, poderíamos enxergar uma pequena contradição com aquilo que o próprio crítico considera fundamental, ou seja, o cruzamento da história com a geografia, ambas determinadas e determinantes na relação tradição/inovação. Acho porém que, sublinhando o papel da forma, Asor Rosa não quer de jeito nenhum indicar uma predeterminação do discurso historiográfico, limitado apenas a obras "formalmente" ortodoxas, mas, isso sim, chamar a atenção para um elemento substancial (a forma do conteúdo) que não exclui nem apaga a heterodoxia, instituindo porém um limiar - embora poroso, transponível - para a definição do literário. Para ser mais claro, até o limite da tautologia, é impossível fazer história da literatura sem pelo menos identificar o objeto a ser historiado, evitando mergulhar (para retomar a conhecida imagem de Hegel) numa noite "em que todas as vacas são pardas". 
Dito isto, fica porém a questão de como colocar a "obra” num contexto de "obras" e de como ilustrar a interferência entre estas e outros contextos (o político, o social, o antropológico...): questão fundamental e fundadora duma visão diacrônica da experiência literária. A resposta dada por Asor Rosa é articulada e, de qualquer modo, "aberta":

A noção que sugerimos utilizar para definir o complexo de fatos organizáveis na literatura é aquela de sistema. A noção de sistema alude seja a um caráter de especificidade e de autonomia a respeito de outros fatos organizáveis em sistemas diversos, seja à relação constantemente interativa existente entre cada uma das partes que a compóem e a totalidade.

Como se vê, Asor Rosa compartilha com Antonio Candido - embora a partir de pressupostos teóricos bem diferentes e sem, obviamente, citar o estudioso brasileiro - a conclusão de que só encarando a literatura como sistema é possível chegar a falar dela de forma orgânica. ${ }^{5}$ E também o crítico italiano se dá conta do perigo em aplicar uma noção tão pouco elástica a um corpus textual e a um discurso em perene transformação:

Uma dificuldade teórica não banal é (...) que o sistema literário (...) não é apenas, como acontece com outras disciplinas, uma pura abstração teórica, fixada na sua própria sincronia, mas é uma estrutura evolutiva com uma rica e determinante caracterização diacrônica: ou seja, é um sistema com uma dupla dimensão temporal, aquela do imediato presente e aquela, de forma nenhuma dissociável da outra, da série passado-presente-futuro.

A conclusão, nesse sentido, remete para uma visão organicista do discurso literário em que "a mais imperceptível das mudanças seria gerada pelo conjunto das leis gerais que regulam a vida desse organismo, e estaria basicamente virada para a regeneração do próprio sistema”*

Esta visão do campo literário como "campo de tensôes"* pode então remeter o discurso teórico sobre a noção de sistema tanto para as consideraçôes de Deleuze a respeito dela ("cada estrutura apresenta estes dois aspetos: um sistema de relações diferenciais, segundo as quais os elementos simbólicos se determinam de forma recíproca; um sistema de singularidades que corresponde a essas relações e delineia o espaço da estrutura. Cada estrutura é uma

\footnotetext{
${ }^{5}$ Convém apenas lembrar, neste mesmo âmbito problemático, outro estudo fundamental de um grande crítico italiano: Guglielmi, Guido La letteratura come sistema e come funzione. Torino: Einaudi, 1967).
}

" (ASOR ROSA, Alberto. "Letteratura, testo, società". Em: Asor Rosa, A. (org.). Letteratura italiana. Torino: Einaudi, 1982, v. I: 17)

(Idem: 18)

* (Idem.)

"(Idem.) 
•(DELEUZE, Gilles. "À quoi reconnaît-on le structuralisme?". Em: CHÂTELE, F. (org.). Histoire de la philosophie. Idées, doctrines. Paris: Hachette, 1973, v. VIII (Le XXe siècle); trad. ital.: Milano: Rizzoli, 1975: 200.)

(DELEUZE, 2007: 20.)

-(ASOR ROSA, 1982: 18.)

(Idem: 20.) multiplicidade",$^{*}$ quanto para a interpretação que o mesmo filósofo forneceu para o conceito foucauldiano de "dispositivo" ("os dispositivos são então compostos por linhas de visibilidade, de enunciação, linhas de força, linhas de subjetivação, de fenda, linhas de racha, de fratura que se entrelaçam e se emaranham"*). E tudo isso leva a pensar que, embora exista, em via de regra, um paradigma (do) "literário" e uma "abstração extrema e última (...) que é a literatura mundial", aquilo com que uma história literária nacional deve lidar é uma agregação precária de instâncias (linguagens, discursos, poderes...), cada uma gerando o seu próprio espaço e tempo - a sua própria norma, enfim:

Trata-se de conceber o fenômeno que aqui nos interessa como aquele que resulta da existência de sistemas diferentes reciprocamente permeáveis, os quais, quando entram em contato, operam uma transmutação mútua de códigos: a mesma coisa pode ser dita várias vezes em modos diferentes; o conteúdo histórico é "registrado" pela linguagem ou pelas linguagens literárias, de modo que o fluxo de informações assume a certa altura aquela forma e não outra.

O panorama historiográfico se torna assim irregular e multilinear, abandonando qualquer confiança no modelo cronológico e conseqüencial clássico que, na Itália, toma forma e força no século XIX com Francesco De Sanctis, lendo a história literária a partir do projeto de unificação nacional - recém completado na altura em que ele escreveu a sua Storia della letteratura italiana (187071). Como Asor Rosa sublinha, a diferença entre o "diagrama" de De Sanctis e aquele proposto por ele consiste, justamente, num uso diferente do tempo, não ligado a uma visão linear e teleológica, mas, isso sim, a uma concepção multilinear e aberta, colocada na contramão da história "clássica":

A série cronológica pura acabará tendo uma importância menor de uma linha mais movimentada e quebrada, em que a relevância atribuída a um só centro geográfico-cultural poderá ser ainda maior do que aquela atribuída na mesma fase ao "desenho" nacional de conjunto (...). É muito importante compreender que, nesta visão, a história não é negada, mas deve aparecer como o tecido que emerge no fim da espessa e progressiva textura de todos aqueles fios, os quais

${ }^{6}$ É significativo que esta definição de Deleuze seja retomada por Ilja Prigogine e Isabelle Stengers quase no fim da entrada Sistema, escrita por eles para a Enciclopedia da Editora Einaudi. (v. 12, Torino, 1983: 1019) A este mesmo texto remete também Asor Rosa para explicar aquilo que ele entende com o termo "estrutura", juntando porém ainda uma alusão ao famoso trabalho de Jurij M. Lotman sobre a Estrutura do texto poético (trad. it.: Milano: Mursia, 1975: 75-100). 
permitem a análise e o conhecimento do texto, dos grupos de textos, dos gêneros, e assim por diante. Em suma, a "história da literatura italiana" é um a posteriori, procedente da concreta demonstração do fato que existe uma "literatura italiana".

Esta história policêntrica precisa, enfim, de uma cronologia também plural, que disseminaria os fatos literários dentro de uma geografia acidentada e cheia de fendas, embora atravessada pela dialética inelutável entre tradição e inovação. Na opinião de Asor Rosa, de fato, "tempo, espaço e a dupla tradição-inovação, considerados em conjunto, fundam a tridimensionalidade da historiografia literária", furtando-a ao "domínio dos gêneros literários discursivos e fundamentalmente retóricos" e incluindo-a no "domínio dos gêneros interpretativos e por tendência científicos". *

Esta procura de uma função hermenêutica, ou melhor, este desejo de produzir uma historiografia literária que não reflita uma ordem temporal absoluta, mas que, ao contrário, crie o seu próprio tempo (e o seu próprio espaço), corresponde, a meu ver, ao intuito de incluir a crise epistemológica a que aludi no início deste ensaio dentro de um discurso analítico sobre a literatura, isto é, de levar em conta o estatuto continuamente redefinido e aberto do "literário", marcado por uma série, hipoteticamente infinita, de mudanças, de interferências, de "catástrofes" e de reorganizaçōes dentro de novas constelações de sentido. Não por acaso, na sua introdução metodológica à Letteratura italiana, Asor Rosa aponta preliminarmente para aquela que ele considera uma quebra ou, justamente, uma "catástrofe" dentro do diagrama imaginado por ele, chegando até a datar de modo pontual esta crise entre 1630 e 1640: depois desta data, a rigor, assistimos ao nascimento de uma outra "literatura italiana”, com outras preocupaçōes e outros registros. Mais do que "uma linha contínua de decadência", surge assim, a partir da metade do século XVII, um panorama que se apresenta "quebrado, retorcido, incerto, muitas vezes dificilmente penetrável" . ${ }^{*}$

Constatação ou opinião que leva a considerar, mais uma vez, a história na sua condição ao mesmo tempo sistemática e hipotética, que se alastra por tempos e espaços dificilmente redutíveis à unidade:

\footnotetext{
${ }^{7}$ De resto, o próprio Asor Rosa "quebrou" também a continuidade do discurso literário do século XX em três momentos (ou tempos) distintos no seu livro Un altro Novecento, (Firenze: La Nuova Italia, 1999) depois reeditado (e aumentado) sob o título significativo: Novecento primo, secondo e terzo (Milano: Sansoni, 2004).
} 
(FOUCAULT, Michel. L'archéologie du savoir. Paris: Gallimard, 1969; trad. ital.: Milano: Rizzoli, 1971: 152.)

(ASOR ROSA, 1982: 28.) (ASOR ROSA, 1995: 11.)
Se, por exemplo, não a olhamos mais (...) seguindo a série cronológica, que vai da origem até os nossos dias, e a encaramos na sua estrutura vertical, nos damos conta de que na literatura italiana, a um forte centralismo de natureza essencialmente retórico-ideológica, corresponde uma produção literária densamente articulada nas realidades regionais e locais. Se, por isso, vamos suspender por instantes o nosso olhar diacrônico e tentamos fixar a perfeita sincronia dum determinado momento histórico, o nosso famoso diagrama deveria ser despedaçado em vários pontos e adequado, à custa de muito trabalho, a um quadro composto por multíplices elementos extremamente diversificados entre si.

Como se vê, muito (quase tudo) depende da ótica pela qual se observa a história literária italiana: embora "por tendência científica” (ou exatamente por isso), a avaliação dos fenômenos (das obras) deve-se colocar numa perspectiva de relativismo em que nada parece firme senão o lugar de produção, ligado por sua vez a um tempo multiplicado, funcionando ou procedendo de modo específico.

Uma frase muito conhecida de Michel Foucault, ainda tributária do pensamento nietzschiano, afirmava que a descrição do arquivo "nos afasta das nossas continuidades; dissipa aquela identidade temporal em que amamos nos contemplar para exorcizar as fraturas da história; corta o fio das teleologias transcendentais: e, lá onde o pensamento antropológico interrogava o ser do homem ou a sua subjetividade, ela faz brilhar o outro e o externo", chegando assim a estabelecer "que nós somos diferença, que a nossa região é a diferença dos discursos, a nossa história a diferença dos tempos, o nosso eu a diferença das máscaras". . Considerando a concepção inovadora da historiografia literária ilustrada por Asor Rosa e levando em conta o fato de que nas palavras do filósofo francês possa talvez ser identificado o cerne de toda a sua reflexão, é com certeza possível também supor que aqui, nesse hipotético cruzamento entre teoria e prática da história, se joguem os destinos de uma nova visão do "dispositivo" literário, não mais ligada a uma conseqüencialidade que conecta o antes ao depois, mas a uma "disposição", justamente, mais articulada e "dispersa" dos fatos artísticos, que ilumina a compenetração e a diferença como fator de análise e de compreensão do(s) discurso(s).

Nesse sentido, o estudo e a ilustração sistemática da literatura nacional responderia a uma "estratégia", ou melhor, corresponderia a uma "estratégia de conhecimento" na qual os fatores movediços da interpretação no interior de um tempo determinado e da deslocação ao longo de um espaço fragmentado se combina- 
riam de forma precária e reversível - "crítica”, em sentido pleno -, abrindo e fechando ao mesmo tempo as fronteiras entre os gêneros, os sistemas de significação, as linguagens, as próprias noções de "literaturas nacionais". E quero aqui mencionar um exemplo dessa visão da literatura em tempo de crise, apontando para outra obra historiográfica "monumental" projetada e editada por outro estudioso italiano: refiro-me aos cinco grandes volumes de Il Romanzo que Franco Moretti organizou e publicou, ainda pela editora Einaudi, de Turim.*

Neste caso, não podemos contar com uma introdução metodológica que nos levasse a entender de imediato o desenho e a lógica geral à qual a obra se submete - a menos que se considerem como tal as duas páginas escassas em que o organizador fala da gênese e das transformaçôes do gênero romanesco num contexto global. Mesmo assim, juntando esta sucinta informação aos outros textos críticos escritos por Franco Moretti (que pertence a outra geração e a outro horizonte teórico em relação a Asor Rosa e que atualmente é professor de Literatura Comparada na Universidade de Stanford, na Califórnia), podemos reconstruir o quadro, ou pelo menos, a moldura teórica em que ele instala o seu projeto de história do romance. De fato, se no breve prefácio aos cinco volumes ele aponta, de modo genérico, para "uma história milenária; uma morfologia proteiforme; uma geografia planetária”, enquanto elementos distintivos da civilização romanesca, para entender a sua nova interpretação desse gênero podemos todavia recorrer a outros três livros que ele tinha publicado, respectivamente, em 1987, em 1994 e em 1997: Segni e stili del Moderno, Opere mondo e Atlante del romanzo europeo.

$\mathrm{Na}$ verdade, o projeto que presidiu à realização de Il Roman$z o$ está já (quase) totalmente inscrito no ensaio abrindo o primeiro desses volumes: "L'anima e l'arpia. Riflessioni sugli scopi e i metodi della storiografia letteraria". Um estudo amplo que por si mesmo, a partir do tema tratado, confirma a atenção que na cultura italiana contemporânea se vem dedicando à redefinição da história literária, num âmbito político-social atravessado por uma crise (ou por uma "catástrofe") profunda, afetando a própria ilusão duma história progressiva, i.e., marcada por um processo irreversível de crescimento e difusão de um bem-estar e de uma liberdade individuais, reflexo, por sua vez, de uma democracia realizada. Entramos, ao contrário, numa fase de indiferença (e de indiferenciação) em que não existe mais uma identidade real e em que, por is-
(MORETTI, Franco. (org.). II romanzo. Torino: Einaudi, 2001-2003, 5 v.) 
so, "quanto mais os dispositivos se tornam invasivos e disseminam o seu poder em cada âmbito da vida, tanto mais o governo enfrenta um elemento inapreensível, que parece se furtar à sua preensão na medida em que se submete obedientemente a ela”*

Poderíamos dizer que a situação política italiana se reflete pelo avesso nessa tentativa polifônica e polimorfa de definir os parâmetros duma outra história, a partir da literatura: retomando o "diagrama" de De Sanctis, que via na literatura o reflexo duma história comum, parece que na crítica contemporânea assistimos, ao invés, à definição duma crise histórica (e epistemológica) em que se espelha um discurso literário muito mais articulado e fragmentário daquele (substancialmente forjado na sua aparente coerência) delineado pelo ilustre estudioso oitocentista. De fato, o traço ligando os novos paradigmas historiográficos é, como já apontei, o desejo de dar conta duma disseminação estética levando a escolhas poéticas peculiares, ou seja, produzindo textos que respondem a contextos plurais e que, ao mesmo tempo, chegam a redefinir ou, pelo menos, a alterar em parte o contexto polimorfo em que são produzidos. No fundo, o resultado a que chegam é que na modernidade (ou talvez, na pós-modernidade) italiana e/ou, lato sensu, européia não existe mais um percurso literário marcado pela homogeneidade, mas vários caminhos virtuais que às vezes se encontram, que podem correr em paralelo até a exaustão ou que podem mesmo não ser nunca atualizados ou praticados de forma sistemática.

Nesta "meada", neste "conjunto multilinear, composto por linhas de natureza diferente", o comum é representado pelos dispositivos formais: por um aparato retórico que não é mais aquilo que gera ou regula o discurso literário sobre a realidade mas é, por outro lado, o produto da evidência e da evolução (científica, política, ética...) do real. Como sublinha Moretti:

Uma história das formas retóricas montadas de modo conseqüente vai levar, com toda probabilidade, a um desmembramento do campo estético. E isso não mais na forma historicista, ou seja, colocando entre parênteses as peculiaridades técnicas das obras para as resolver num genérico "Espírito do tempo" - mas derivando vice-versa justamente da sua materialidade formal a necessidade teórica de desmontar a história da arte, ou da literatura, e de a reescrever apenas como parte duma história dos valores, das estruturas de pensamento em que eles se organizam, das instituições que tendem a promovê-los.

A partir daqui é possível compreender a atenção do estudioso italiano voltada mais para a história de um gênero literário do 
que para uma história literária nacional: o tratamento comparado da "forma-romance" permite manter - na óbvia dispersão espaço-temporal e no "desmembramento do campo estético" - uma fundamental coerência na análise dos vetores sociais e dos recursos técnicos. Coerência, essa, que nenhuma história literária nacional pode conseguir, devendo necessariamente dar conta (e cito um exemplo ilustrado pelo próprio autor) da fortuna do soneto e, ao mesmo tempo, daquela do feuilleton.

Il Romanzo e, antes dele, textos como Opere mondo ou Atlante del romanzo europeo respondem, justamente, a esta exigência de estudar o "dispositivo" ficcional, ilustrando a gênese e a difusão (ou profusão) tanto da forma épica quanto do discurso narrativo do ponto de vista de um aparato ideológico, de contextos sociais e de fatores institucionais que parecem destinados a produzir uma forma retórica bastante coesa, no seu inevitável polimorfismo e na sua constante abertura - visto que assenta numa história considerada "uma gigantesca metáfora da geografia”. O resultado é um trabalho, muito interessante e original, sobre os mapas em que se deposita uma certa imagem da irradiação histórica e da defasagem temporal do discurso romanesco, que acaba, senão numa desmontagem do cânone, numa reflexão, isto sim, sobre os efeitos que um estudo da distribuição geográfica das obras literárias pode ter numa reconfiguração do tempo histórico - sublinhando, finalmente, o seu fatal anacronismo e o seu caráter "intempestivo"- e do valor relativo de cada texto em relação aos outros. Já em "L'anima e l'arpia” Moretti propunha:

Uma história literária mais "lenta”. E mais "descontinua”. Atualmente, para segmentar o continuum histórico, a crítica recorre a critérios demais, e demasiado heterogêneos (...). O resultado final é, na maioria dos casos, uma grande teia de aranha pegajosa em que os saltos históricos perdem toda limpidez. Se o conceito de gênero literário será elaborado de modo pertinente e sistemático, ele poderia contribuir para endurecer as arestas da pesquisa histórica, já que uma história redesenhada segundo princípios estritamente formais será uma história mais rígida, mais fraturada. Não apenas (...) no plano diacrônico, mas também e talvez sobretudo no sincrônico: em cada época coexistem, com efeito, formas simbólicas diversas e até em conflito entre si, e cada uma dotada de uma difusão e de uma duração histórica diferente. A historiografia literária deve ter como fim a representação do seu objeto como uma espécie de campo magnético, em que o equilíbrio ou o desequilíbrio global não é senão o resultado de cada uma das forças ativas no interior dele.
* (MORETTI, Franco. Opere mondo. Saggio sulla forma epica dal Faust a Cent'anni di solitudine. Torino: Einaudi, 1994: 49.) 
(MORETTI, Franco. Atlante del romanzo europeo. 1800-1900. Torino: Einaudi, 1997: 202.)
Sendo este o alvo, parece óbvio que a conclusão vai ser uma visão que, saindo do particular, chega ao geral sem desdizer ou apagar o ponto de partida: um grande afresco, fatalmente incompleto e fragmentado, que, partindo da origem do romance na Inglaterra e na França do começo do século XIX, acaba por considerar as articulações deste gênero nos âmbitos culturais marginais. Valendose, em particular, das teorias de Roberto Schwartz, Moretti pode assim afirmar, na parte final do seu Atlas, que a retomada da "forma-romance" (ou das idéias sobre as quais ela assenta) fora do seu lugar de origem chega a produzir uma nova geografia e uma outra história: "de um novo espaço a uma nova forma - que é enfim um novo espaço." E ele conclui o seu livro com uma pergunta: "será sempre tão estreito o enredo entre história e geografia literária?”* Questão, esta, que atravessa também a obra de Asor Rosa e que tem na imagem da literatura como "campo de tensões" e/ou como "campo magnético" o seu cerne e também a sua resposta.

Concluindo este discurso, fatalmente parcial e incompleto, sobre a preocupação montante, nas últimas décadas, com a historiografia literária (ou com a historiografia tout court - mas isto remeteria realmente para uma outra história...), acho que podemos, embora de forma provisória e problemática, retomar a afirmação inicial sobre a revisão da relação com o passado em épocas de crise, aventando a hipótese de que a Itália mostra, de modo claro, que a situação "catastrófica” pela qual tem passado (mudança radical dos valores sociais, fim das ideologias, evolução/involução da cidadania e da representatividade política - encontrando, aliás, no momento em que estou escrevendo uma confirmação "eleitoral" clamorosa) gerou uma nova preocupação com a preservação e a valorização da memória cultural. ${ }^{8}$ Num contexto nacional (e europeu) que considera um mérito a rasura contínua dos fatos, em prol de uma desmemória coletiva e de uma homologação baseada na defesa feroz dos privilégios, o resgate - através da sua "profanação" - do dispositivo literário (ou, mais em geral, artístico) representa uma linha

\footnotetext{
${ }^{8}$ Entre os inúmeros exemplos dessa atenção renovada para a historiografia literária e/ou para a salvaguarda do patrimônio cultural na Itália, poderia citar - para além dos estudiosos mencionados no presente ensaio - pelo menos os nomes de grande críticos como Cesare Segre, Giulio Ferroni, Romano Luperini e Costanzo Di Girolamo. A lista poderia obviamente ser muito mais comprida, mas estes nomes são apenas o indício de um fenômeno (historiográfico, certamente, mas também político e intelectual) muito mais amplo e articulado.
} 
de resistência fundamental contra essa máquina governamental girando em falso e levando à "catástrofe".

Descobrir aquilo que não pode nem deve ser governado (o tornar-se sujeito do homem contemporâneo; o seu direito a um imaginário em que continuam se manifestando as instâncias heteróclitas de um "uso comum", de uma participação solidária ao discurso literário, atravessando e contaminando continuamente tempos e espaços irredutíveis); estudar aquilo que, pelo fato de ser programaticamente "inatual", se furta ao esquecimento e ao fim da história fica sendo, talvez, a única salvação possível no interior deste presente insosso e sem nome.

\section{Ettore Finazzi-Agrò}

Professor Titular de Literaturas Portuguesa e Brasileira na Faculdade de Ciências Humanas da Universidade de Roma "La Sapienza". Publicou livros sobre Clarice Lispector e Guimarães Rosa, e organizou, com outros colegas, duas coletâneas de ensaios sobre o "trágico moderno" no âmbito da literatura brasileira. É autor de vários livros e de muitos artigos sobre vários aspectos das culturas de língua portuguesa.

\section{Resumo}

A partir das reflexões teóricas elaboradas na passagem entre o século XX e o século XXI, o presente texto tenta dar conta tanto da relação entre historiografia e produção literária, quanto da relação entre lógica temporal e distribuição espacial, que vêm sendo repensadas pela crítica italiana dos últimos anos. Nessa nova constelação problemática, o que se pode entrever é uma forte preocupação com o horizonte histórico e com a deriva da forma no atual contexto nacional. As obras consideradas são, em particular, as de Alberto Asor Rosa e de Franco Moretti.

\footnotetext{
${ }^{9}$ Estou parafraseando, aqui, as importantes conclusões de Giorgio Agamben sobre o caráter "invasivo" e sobre a ingerência "catastrófica" dos dispositivos na sociedade contemporânea. (Op. cit.: 32-35) Remeto a este texto também para um esclarecimento sobre a necessidade da "profanação" daquilo que foi "capturado e separado" nos dispositivos, restituindo-os assim ao seu "uso comum".
} 
Key words: Historiography;
Geography; Literature.

Mots-clés: Historiographie Géographie; Littérature.

\section{Abstract}

This text uses the theoretical reflexions elaborated in the transition between the twentieth and the twenty-fist centuries as a basis to try and analyze the relationship between historiography and literary production, as well as the relationship between temporal logics and spatial distribution, which have been reevaluated by Italian criticism in the last years. What can be seen in this new problematic constellation is a strong concern with the historical horizon and the deviations in form of the present national context. The works used are, mostly, those from Alberto Asor Rosa and Franco Moretti.

\section{Résumé}

A partir des réflexions théoriques élaborées dans le passage du XX' ${ }^{\text {ème }}$ au XXI ${ }^{\text {ème }}$ siècle, ce texte essaie de rendre compte autant de la relation entre l'historiographie et la production littéraire que de la relation entre la logique temporelle et la distribution spatiale qui se font repenser par la critique italienne des dernières années. Dans cette nouvelle constellation problématique, ce que l'on peut entrevoir c'est une forte inquiétude devant l'horizon historique et devant la dérive de la forme dans le contexte national actuel. Les œuvres examinées sont, en particulier, celles d'Alberto Asor Rosa et de Franco Moretti. 